\section{Military Technical College Kobry El-Kobbah, Cairo, Egypt}

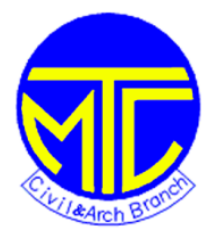
$10^{\text {th }}$ International Conference on Civil and Architecture Engineering ICCAE-10-2014

\title{
Finite Element Analysis of Square Footing Resting on Geosynthetic Reinforced Soil
}

\author{
Ahmed El-Shesheny ${ }^{1}$, Nabil Nagy ${ }^{2}$, Adel Belal $^{3}$ and Ahmed Badawy ${ }^{4}$
}

\begin{abstract}
Bearing capacity of soil is considered an important parameter at which the soil can resist loads above it. Different ways are used to improve the bearing capacity of weak soils. One of the used techniques is the soil reinforcing technique. In this study, the results of numerical simulations on square footings resting on geosynthetic reinforced sand are presented. In order to predict the improvement in the bearing capacity resulting from the usage of the reinforcing layers in the sand, finite element analysis package ANSYS is used. Nonlinear Drucker-Prager's model is used as material model to simulate the soil and Linear Isotropic model is used as material models to simulate the reinforcing layers and the footing respectively. SOLID45 element is used as element type to simulate the soil and the footing and Link8 is used as element type to simulate the reinforcing layers. Numerical model of $150 \mathrm{~mm} \times 150 \mathrm{~mm} \times 25 \mathrm{~mm}$ is used to simulate the square footing and model of $900 \mathrm{~mm}$ x $900 \mathrm{~mm}$ x $600 \mathrm{~mm}$ is used to simulate the soil. Under the effect of both static and dynamic loading two main effective parameters are discussed in this study. The investigated parameters are the number of the reinforcing layers and the depth of the reinforced zone which includes the variation of spacing between the reinforcing layers. The bearing capacity improvement investigation is analyzed.
\end{abstract}

Keywords: Geosynthetic reinforcement, Numerical modelling, Reinforced soil, Square footing.

\section{Introduction}

Using different types of reinforcing layers such, metallic (non-extensible - steel) and nonmetallic (extensible - geosynthetic) to improve the bearing capacity of weak soil is studied. Many researchers have studied the effect of using reinforcing layers to predict the improvement occurred in weak soil under static load [1]-[5]. Most of these studies are on strip or circular footing. But, square footing is a common shape that used in foundations systems; however, some researchers studied it [6]-[11]. The behaviour of strip footing resting on geosynthetic reinforced sand is studied under cyclic loading [12].

\footnotetext{
${ }^{1}$ Civil Eng. Department, Military Technical College - Cairo, EGYPT, Elshesheny.A@gmail.com.

${ }^{2}$ Assoc. Prof. in Civil Eng. Department, Military Technical Collage - Cairo, EGYPT.

${ }^{3}$ Prof. Dr. in Arab Academy for Science, Technology and Maritime Transport.

${ }^{4}$ Mechanical Eng. Department, Military Technical Collage - Cairo, EGYPT.
} 
Series of model footing tests on reinforced sand with different relative densities under vertical cyclic loading is studied [13]. Many studies have shown that using geosynthetic reinforcement to support weak soils is considered an effective method to improve the bearing capacity of the soil and decrease the settlement happened due to the existence of vertical cyclic loading [14]-[15]. The bearing capacity increase and the settlement decrease of strip and square footings resting on geogrid reinforced sand and subjected to the sum of static load and vertical cyclic load is studied [16]-[17].

The main objective of this study is to predict the behaviour of geosynthetic layers in improving the bearing capacity of the square footings. The parameters considered in the model tests are the number of the reinforcing layers and the spacing between them.

\section{Reinforcement Layout and Configuration}

Figure 1 shows the layout of the multi-layer geosynthetic reinforced sand in the model. $\mathrm{N}$ layers of reinforcement, square in shape; of side width $\mathrm{w}$ and they are placed at specific depths. The depth of the first layer measured from the bottom face of the footing is defined as $\mathrm{v}$ and the vertical spacing between consecutive layers of the reinforcement is measured as $\mathrm{h}$. The total depth of reinforced zone measured as $\mathrm{Z}$, where $\mathrm{Z}$ can be calculated as follow:

$$
\mathrm{Z}=\mathrm{v}+(\mathrm{N}-1) * \mathrm{~h}
$$

All these parameters are expressed in non-dimensional form in terms of the footing width as $v / B_{f}, h / B_{f}, w / B_{f}$ and $Z / B_{f}$ (reinforcement depth ratio). In this study, all the previous parameters are considered constant except the number of layers $\mathrm{N}$ and the spacing between layers $\mathrm{v}$ under both, static and dynamic loading.The square footing is measured as $\mathrm{Bf} \mathrm{x} \mathrm{Bf}$.

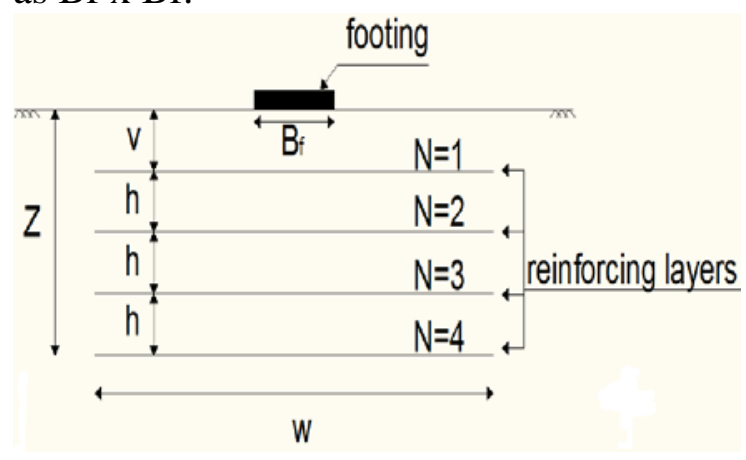

Figure 1: Layout and configuration of geosynthetic layers in the model

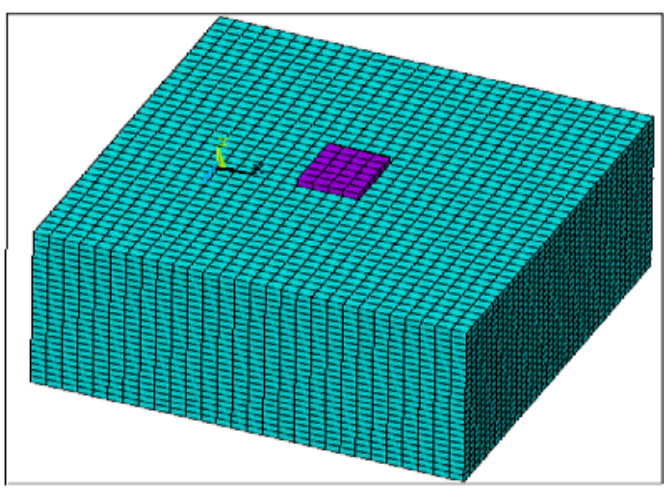

Figure 2: Soil and footing modeling

\section{Numerical Modelling}

In this study, loading tests were carried out on reinforced and unreinforced sand subjected to square footing numerically using ANSYS package. Drucker-Prager's model is used to model the behaviour of the sand [12]. Full 3D model was constructed to simulate the problem, and its dimensions were $900 \mathrm{~mm} \times 900 \mathrm{~mm} \times 600 \mathrm{~mm}$. The outer four sides of the model were restricted to move in direction normal to its plan and free to move in the other directions. The bottom of the model was restricted to move in all directions. The model was divided into a regular grid pattern of 24216 elements (sand and square footing 
model without reinforcing material elements). The initial geostatic stresses were calculated in the model.

\section{Soil Modeling}

The soil used in this study is considered sand of dimensions $=900 \mathrm{~mm} \times 900 \mathrm{~mm} \times$ $600 \mathrm{~mm}$, modulus of elasticity $=4 \times 10^{4} \mathrm{KPa}$, Poisson's ratio $=0.3$, density $=1900 \mathrm{Kg} / \mathrm{m}^{3}$, cohesion $=10 \mathrm{KPa}$, friction angle $=35$ and flow angle $=11$ 。 [13]. A 3D finite element model was used to simulate the sand using Drucker-Prager's as material model and Solid45 as element type [12]. The sand model consists of 24192 elements (only sand model elements), each of 33mm length, 25mm width and 25mm depth as shown in Fig. 2.

\section{Geosynthetic reinforcement modeling}

The reinforcement is modeled using Linear Isotropic model as material model and Link8 as element type, and it was a medium geogrid reinforcement of E=1970MPa and Poisson's ratio $=0.3$. The aperture size of the reinforcement $=33 \mathrm{~mm} \times 25 \mathrm{~mm}$ and the cross-section area of the reinforcement $=9 \mathrm{~mm} \times 2 \mathrm{~mm}$ as shown in Figure 3 .

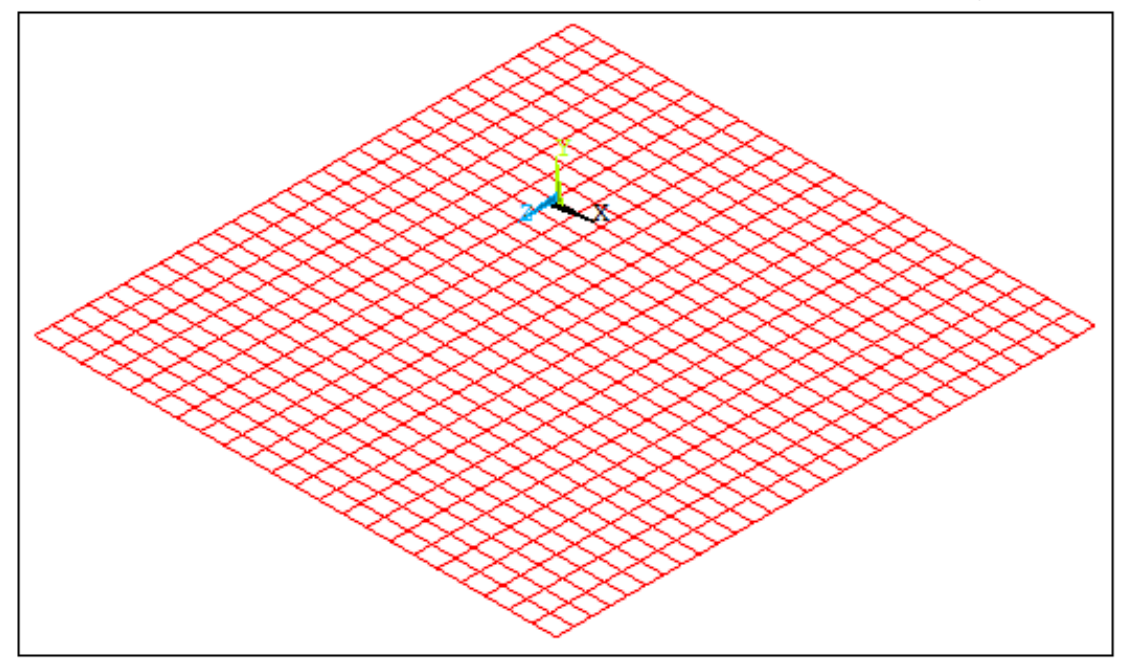

Figure 3: Reinforcing layers modeling

\section{Square footing modeling}

In this study, the square footing was modeled as steel footing of dimensions $=150 \mathrm{~mm} x$ $150 \mathrm{~mm} \times 25 \mathrm{~mm}$, modulus of elasticity $=2.1 \times 10^{11} \mathrm{GPa}$ and Poisson's ratio $=0.3$. The square footing was modeled using Linear Isotropic model as material model and Solid 45 as element type. The square footing model consists of 24 elements, each of 33mm length, 25mm width and 25mm depth as shown in Figure.2.

\section{Comparison between numerical and experimental analysis}

As a result of the absence of practical modeling in this study, validation model is made to ensure the proper use of the finite element analysis modeling. Figure 4 illustrates the pressure-settlement relation for reinforced and unreinforced soil as a result of the use of the finite element package ANSYS and the results from practical study [11]. 


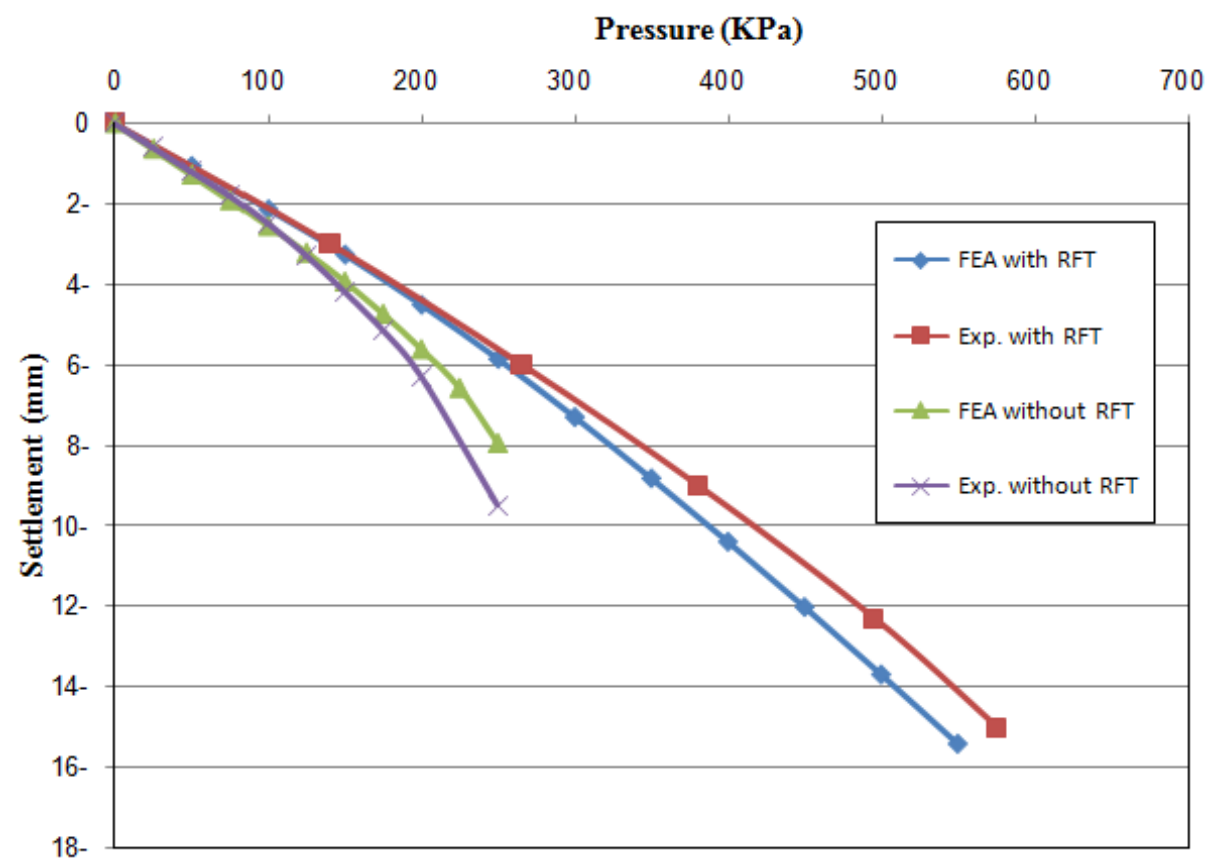

Figure 4: Numerical and experimental analysis comparison.

\section{Static and dynamic load}

In this study, the model is subjected to two cases of loading, static loading case and dynamic loading case. The most common types of dynamic (repeated) loading are load of machine foundations, petroleum tanks and ship repair tracks. Dynamic load amplitude $\mathrm{q}_{\mathrm{dyn}}$ is taken as a percentage of the maximum static load carried by the reinforced sand $\mathrm{q}_{\mathrm{st}}$. The footing is subjected to dynamic load of 25 cycles with frequency of $1 \mathrm{~Hz}$ (harmonic analysis) as shown in Figure 5.

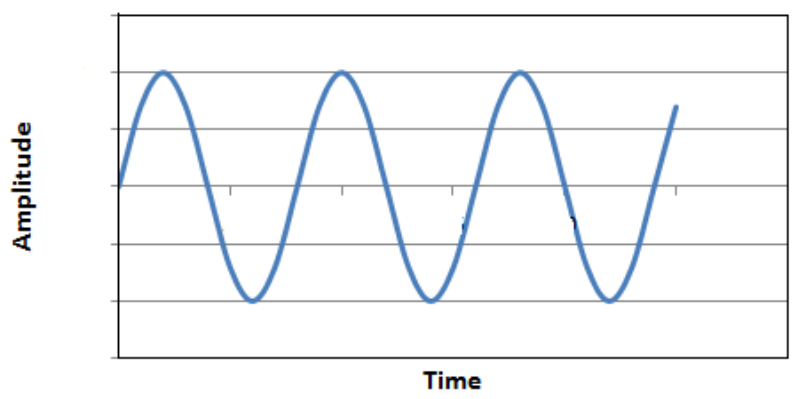

Figure5: Dynamic load (harmonic load).

The applied dynamic load is considered fractions of the uniform static load. The dimensionless factor $r$ represent the ratio of applied dynamic load amplitude relative to the maximum uniform static load carried by the footing in the reinforced sand case $(\mathrm{r}=$ $\mathrm{q}_{\mathrm{dyn}} / \mathrm{q}_{\mathrm{st}}$ ) [18]. Table 1 describes constant and variable parameters in this model under static load. Table 2 describes constant and variable parameters in the model under dynamic load. In this study $\mathrm{v}$ and $\mathrm{h}$ are kept equal in static and dynamic loading. 
Table 1: Constant and variable parameters in the model (static load)

\begin{tabular}{|c|c|c|c|c|}
\hline Case & $\mathbf{v} / \mathbf{B}_{\mathbf{f}}=\mathbf{h} / \mathbf{B}_{\mathbf{f}}$ & $\mathbf{Z} / \mathbf{B}_{\mathbf{f}}$ & $\mathbf{w} / \mathbf{B}_{\mathbf{f}}$ & Type of Geosynthetic Material \\
\hline 1 & $0.333-0.4-0.5-0.667-1$ & 2 & 4 & Medium Geogrid \\
\hline \multirow{3}{*}{2} & 0.333 & 1.33 & 4 & Medium Geogrid \\
\cline { 2 - 5 } & 0.5 & 2 & 4 & Medium Geogrid \\
\cline { 2 - 5 } & 0.667 & 2.67 & 4 & Medium Geogrid \\
\cline { 2 - 5 } & 0.833 & 3.33 & 4 & Medium Geogrid \\
\hline
\end{tabular}

Table 2: Constant and variable parameters in the model (dynamic load)

\begin{tabular}{|c|c|c|c|c|c|}
\hline Case & $\mathbf{v}_{\mathbf{f}} \mathbf{B}_{\mathbf{f}}=\mathbf{h} / \mathbf{B}_{\mathbf{f}}$ & $\mathbf{Z} / \mathbf{B}_{\mathbf{f}}$ & $\mathbf{w} / \mathbf{B}_{\mathbf{f}}$ & $\mathbf{( r ~ \% )}$ & $\begin{array}{c}\text { Type of } \\
\text { Geosynthetic } \\
\text { Material }\end{array}$ \\
\hline 1 & $0.4-0.5-0.667-1$ & 2 & 4 & $5-10-25-40-55-70-85$ & Medium Geogrid \\
\hline \multirow{2}{*}{2} & 0.333 & 1.33 & 4 & $5-10-25-40-55-70-85$ & Medium Geogrid \\
\cline { 2 - 6 } & 0.5 & 2 & 4 & $5-10-25-40-55-70-85$ & Medium Geogrid \\
\cline { 2 - 6 } & 0.667 & 2.67 & 4 & $5-10-25-40-55-70-85$ & Medium Geogrid \\
\hline
\end{tabular}

\section{Result and Discussion}

A series of 3D finite element analysis were performed in order to investigate the improvement in bearing capacity and the settlement due to using reinforced sand under a square footing exposed to static and dynamic load.

\section{Static loading analysis}

A total of 118 analysis cases were conducted using the 3D finite element method to investigate the behaviour of reinforced sand under uniform static load.

\section{Effect of reinforcing layers number}

The number of used reinforcing layers is considered an important parameter to be studied. In this study, two, three, four, five and six layers of the reinforcing material have been used. Table 3 shows the different parameters used in this case (case 1).

Table 3: Different parameters in case 1.

\begin{tabular}{|c|c|c|c|}
\hline $\mathbf{Z} / \mathbf{B}_{\mathbf{f}}$ & $\mathbf{w} / \mathbf{B}_{\mathbf{f}}$ & $\mathbf{M . G}$ & $\mathbf{N}$ \\
\hline 2 & 4 & $\mathrm{E}=1970 \mathrm{MPa}$ & $2-3-4-5-6$ \\
\hline
\end{tabular}

Therefore,

\begin{tabular}{|c|c|c|c|c|c|}
\hline $\mathbf{N}$ & $\mathbf{2}$ & $\mathbf{3}$ & $\mathbf{4}$ & $\mathbf{5}$ & $\mathbf{6}$ \\
\hline $\mathrm{h}=\mathrm{v}$ & $150 \mathrm{~mm}$ & $100 \mathrm{~mm}$ & $75 \mathrm{~mm}$ & $60 \mathrm{~mm}$ & $50 \mathrm{~mm}$ \\
\hline $\mathrm{h} / \mathrm{B}_{\mathrm{f}}=\mathrm{v} / \mathrm{B}_{\mathrm{f}}$ & 1 & 0.667 & 0.5 & 0.4 & 0.333 \\
\hline
\end{tabular}

Figure 6 illustrates the square footing settlement in the sand (reinforced and unreinforced) corresponding to the difference in the number of layers under uniform static loading.It is concluded that the effect of using four, five and six layers of the reinforcing layers is almost the same, and then using four layers is considered the optimum solution. 


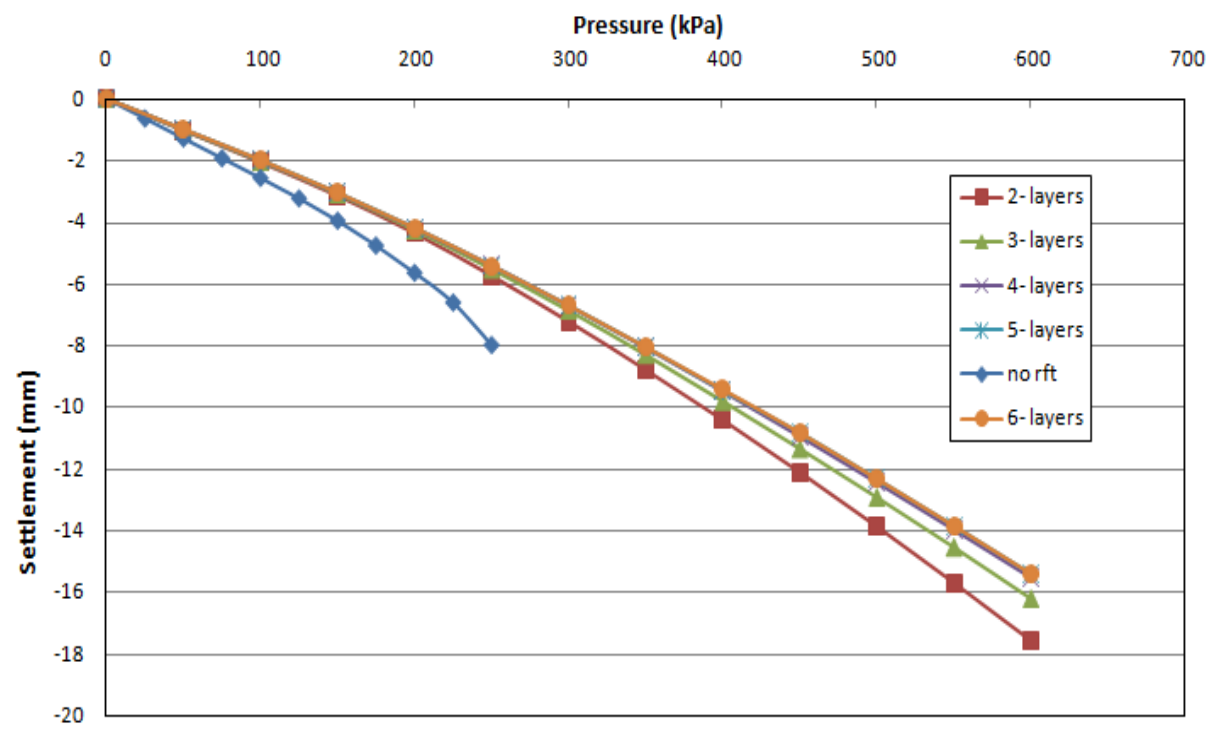

Figure 6: Effect of layers number

\section{Effect of the depth of the reinforced zone}

The spacing between reinforcing layers is considered an important parameter to be studied. In this study, the spacing between reinforcing layers has been changed to get the optimum depth. Table 4 shows different parameters used in this case (case 2).

Table 4: Different parameters in case 2.

\begin{tabular}{|c|c|c|}
\hline $\mathbf{w} / \mathbf{B}_{\mathbf{f}}$ & $\mathbf{N}$ & M.G \\
\hline 4 & 4 & E=1970 (MPa) \\
\hline
\end{tabular}

Then, due to the change in the spacing between the reinforcing layers, the depth of the reinforced zone will be changed as shown in Table 5 .

Figure 7 illustrates the square footing settlement in the sand corresponding to the variation in the spacing between the reinforcing layers and the reinforced zone depth under uniform static loading.

Table 5: Values of the reinforced zone depth.

\begin{tabular}{|c|c|c|c|c|}
\hline $\mathbf{v}=\mathbf{h}(\mathbf{m m})$ & $\mathbf{5 0}$ & $\mathbf{7 5}$ & $\mathbf{1 0 0}$ & $\mathbf{1 2 5}$ \\
\hline $\mathrm{Z}(\mathrm{mm})$ & 200 & 300 & 400 & 500 \\
\hline $\mathrm{Z} / \mathrm{B}_{\mathrm{f}}$ & 1.333 & 2 & 2.667 & 3.333 \\
\hline
\end{tabular}

It is concluded that the effect of using $\mathrm{Z} / \mathrm{B}_{\mathrm{f}}=1.33$ and 2 is almost the same. Then, using $\mathrm{Z} / \mathrm{B}_{\mathrm{f}}=2$ is considered the optimum solution and the optimum spacing between the reinforcing layers is half the width of the footing.

\section{Dynamic loading analysis}

A total of 58 analysis cases were conducted using the 3D finite element method to investigate the behaviour of reinforced sand under dynamic (repeated) load. 


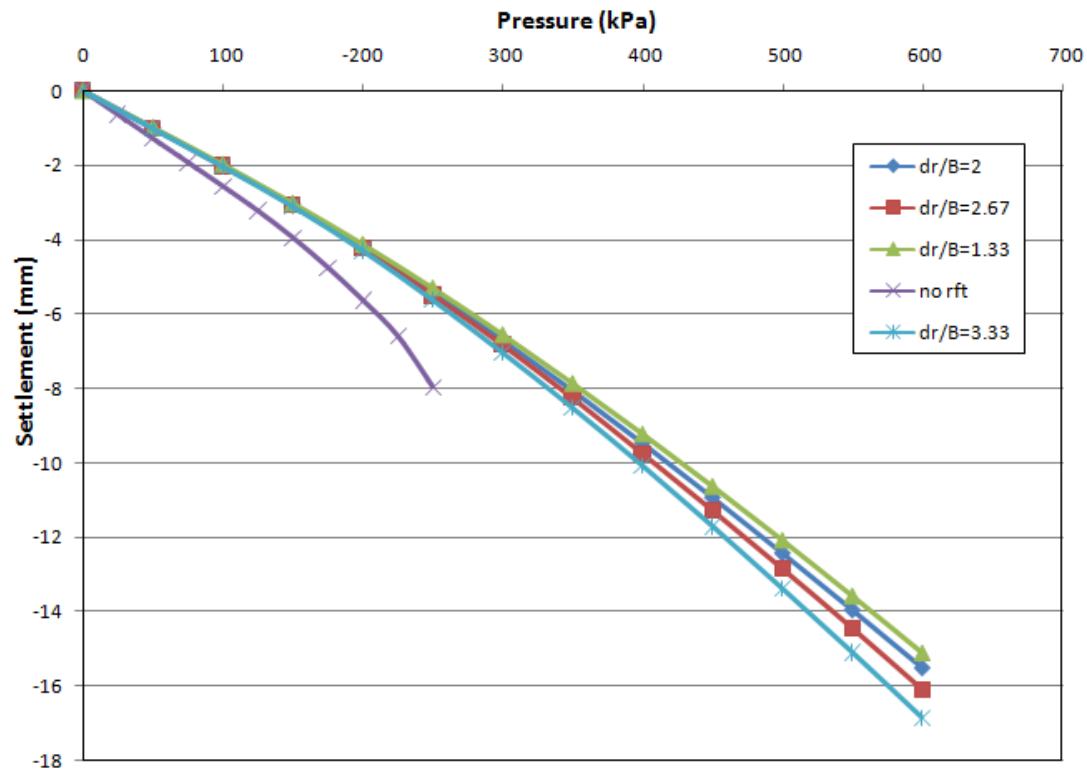

Figure 7: Effect of depth of the reinforced zone and spacing between layers

\section{Effect of reinforcing layers number}

The number of used reinforcing layers is considered an important parameter to be studied. In this study, two, three, four and five layers of the reinforcing material have been used. Table 6 shows the different parameters used in this case (case 3).

Table 6: Different parameters in case 3.

\begin{tabular}{|c|c|c|c|}
\hline $\mathbf{Z} / \mathbf{B f}$ & W/Bf & M.G & N \\
\hline 2 & 4 & $\mathrm{E}=1970 \mathrm{MPa}$ & $2-3-4-5$ \\
\hline
\end{tabular}

Therefore,

\begin{tabular}{|c|c|c|c|c|}
\hline $\mathbf{N}$ & $\mathbf{2}$ & $\mathbf{3}$ & $\mathbf{4}$ & $\mathbf{5}$ \\
\hline $\mathrm{h}=\mathrm{v}$ & $150 \mathrm{~mm}$ & $100 \mathrm{~mm}$ & $75 \mathrm{~mm}$ & $60 \mathrm{~mm}$ \\
\hline $\mathrm{h} / \mathrm{Bf}=\mathrm{v} / \mathrm{Bf}$ & 1 & 0.667 & 0.5 & 0.4 \\
\hline
\end{tabular}

Figure 8 shows the square footing settlement in the sand (reinforced and unreinforced) corresponding to the difference in the number of layers under dynamic (repeated) loading. It is concluded that the effect of using three, four and five layers of the reinforcing layers is almost the same, and then using four layers is considered the optimum solution.

\section{Effect of the depth of the reinforced zone and spacing between reinforcing layers}

The spacing between reinforcing layers is considered an important parameter to be studied. In this study, the spacing between reinforcing layers has been changed to get the optimum depth. Table 7 shows different parameters used in this case (case 4).

Table 7: Different parameters in case 4.

\begin{tabular}{|c|c|c|}
\hline $\mathbf{w} / \mathbf{B}_{\mathbf{f}}$ & $\mathbf{N}$ & M.G \\
\hline 4 & 4 & $\mathrm{E}=1970(\mathrm{MPa})$ \\
\hline
\end{tabular}


Then, due to the change in the spacing between the reinforcing layers, the depth of the reinforced zone will be changed as shown in Table 8.

Pressure (KPa)

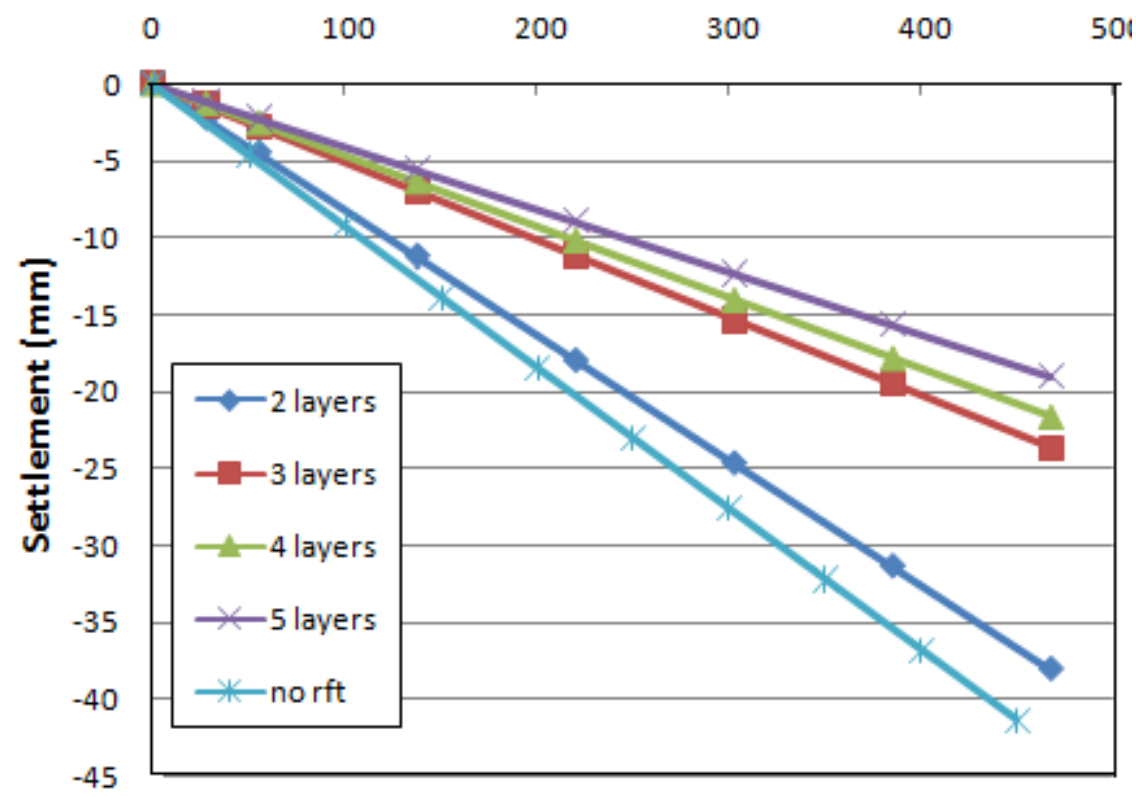

Figure 8: Effect of layers number.

Table 8: Values of the reinforced zone depth.

\begin{tabular}{|c|c|c|c|}
\hline $\mathrm{v}=\mathrm{h}(\mathrm{mm})$ & 50 & 75 & 100 \\
\hline $\mathrm{Z}(\mathrm{mm})$ & 200 & 300 & 400 \\
\hline $\mathrm{Z} / \mathrm{B}_{\mathrm{f}}$ & 1.333 & 2 & 2.667 \\
\hline
\end{tabular}

Figure 9 shows the square footing settlement in the sand corresponding to the variation in the spacing between the reinforcing layers and the reinforced zone depth under dynamic (repeated) loading.

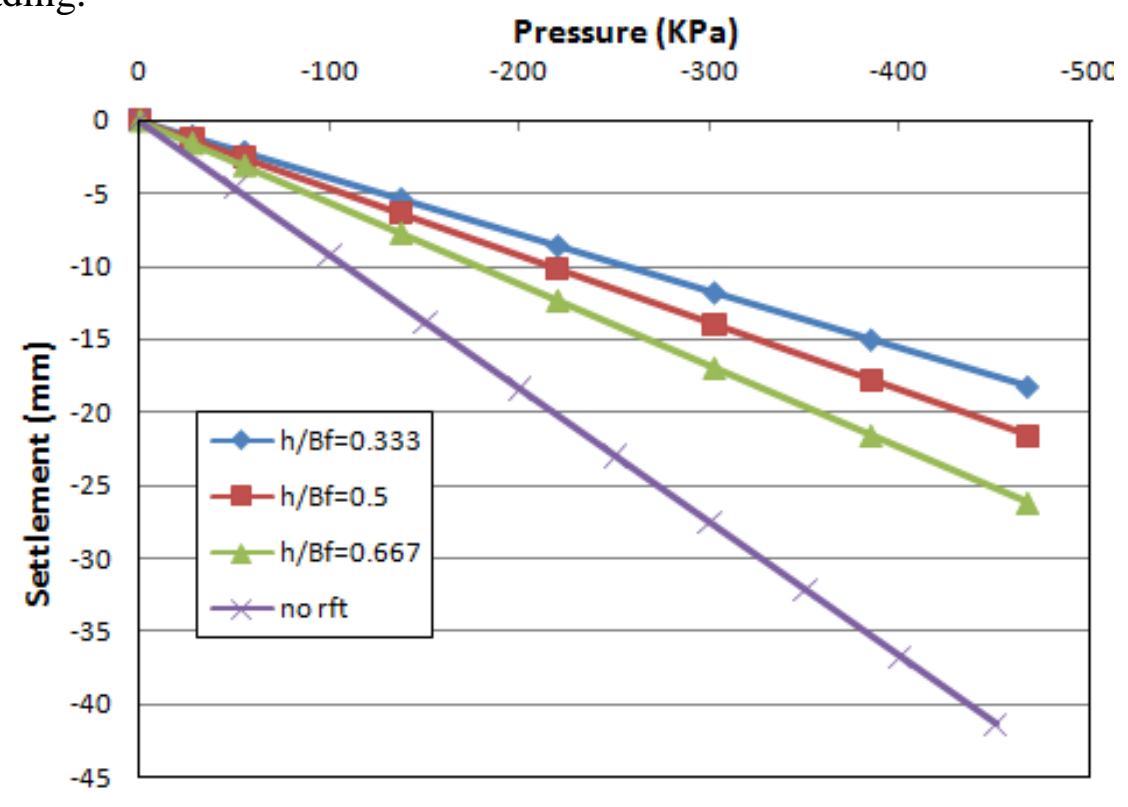


Figure 9: Effect of the depth of the reinforced zone and spacing between layers

It is concluded that the effect of using $\mathrm{Z} / \mathrm{Bf}=1.33$ and 2 is almost the same. Then, using $\mathrm{Z} / \mathrm{B}_{\mathrm{f}}=2$ is considered the optimum solution and the optimum spacing between the reinforcing layers is half the width of the footing.

\section{Bearing capacity improvement ratio (Ir)}

The improvement in the bearing capacity of the soil is defined as improvement ratio (Ir), and it is expressed through non-dimensional units as shown in the following equation

$$
\mathrm{Ir}=(1-(\mathrm{Q} / \mathrm{Qr})) * 100
$$

where, $Q_{r}$ is the bearing capacity of the reinforced soil at certain settlement and $\mathrm{Q}$ is the bearing capacity of unreinforced soil at the same settlement. This ratio is measured at the maximum measured settlement.

In static analysis, Iris measured at the maximum settlement in the case of using six layers of the reinforcing layers and in the case of using $\mathrm{Z} / \mathrm{B}_{\mathrm{f}}=1.333\left(\mathrm{~h} / \mathrm{B}_{\mathrm{f}}=0.333\right)$.

In dynamic analysis, Ir measured at the maximum settlement in the case of using five layers of the reinforcing layers and in the case of using $\mathrm{Z} / \mathrm{B}_{\mathrm{f}}=1.333\left(\mathrm{~h} / \mathrm{B}_{\mathrm{f}}=0.333\right)$.

Figure 10shows that, the increase in the number of the reinforcing layers increases the bearing capacity of the sand until we reach four layers of the reinforcing material. Using more than four layers gives insignificant improvement in the bearing capacity of the soil. Figure 11shows that, the less the reinforced zone depth (small distance between reinforcing layers), the more the bearing capacity becomes until reinforced depth zone that gives $\mathrm{Z} / \mathrm{Bf}=2(\mathrm{~h} / \mathrm{Bf}=0.5)$. When using $\mathrm{Z} / \mathrm{Bf}$ more than 2 , the increase in the bearing capacity becomes insignificant under both uniform static and dynamic loading.

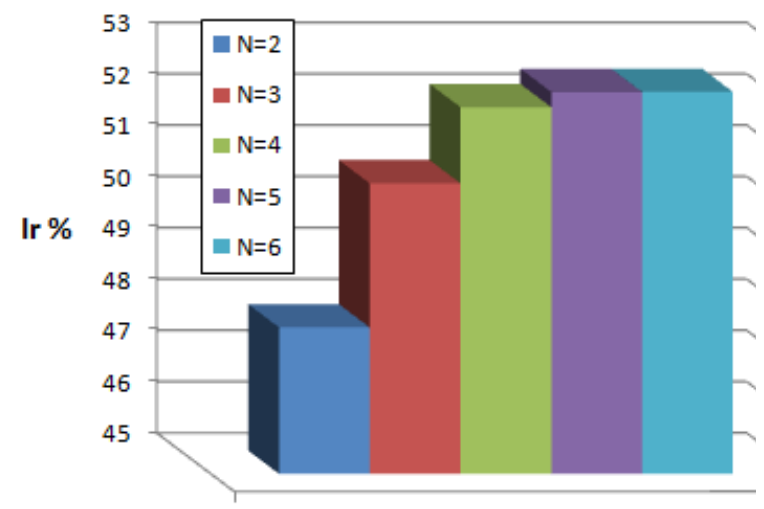

Uniform static loading

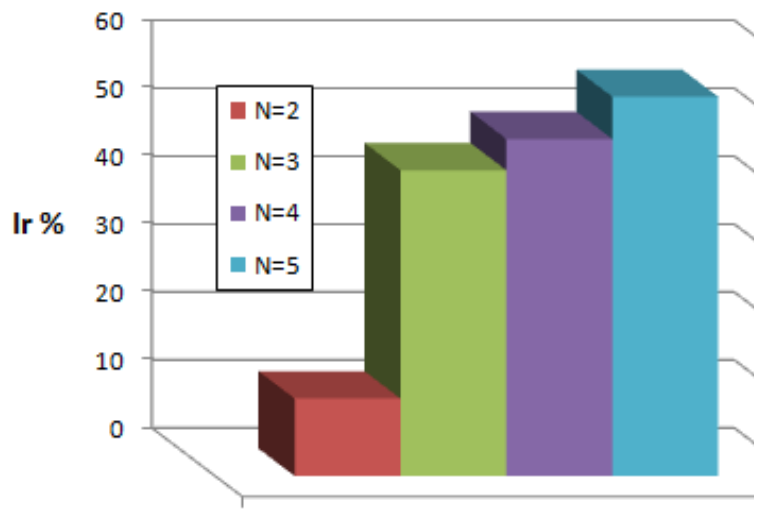

Dynamic loading

Figure 10: Improvement ratio between number of reinforcing layers and settlement 


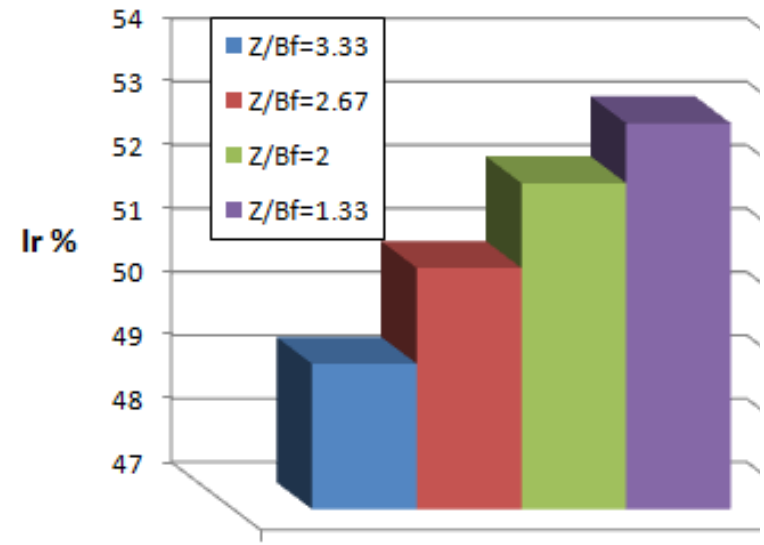

Uniform static loading

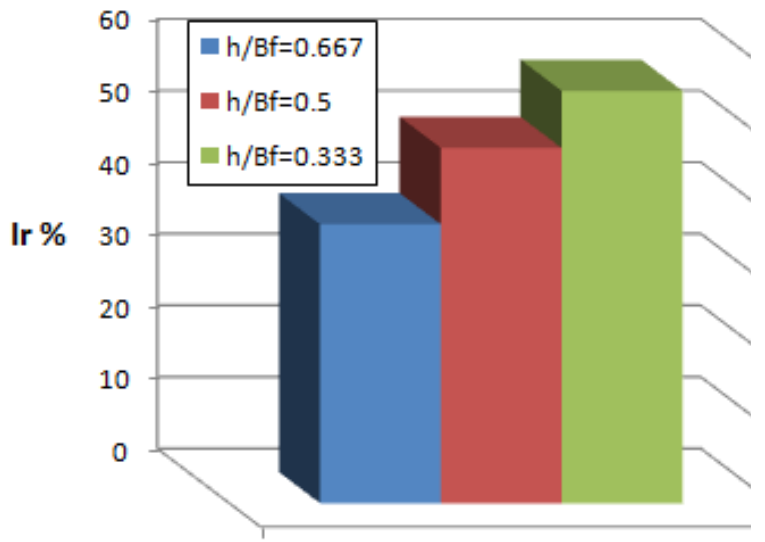

Dynamic loading

Figure 11: Improvement ratio between depth of the reinforced zone

\section{CONCLUSION}

According to the results obtained from the previous numerical studies, the following conclusions can be made on the behaviour of square footing resting on sand reinforced with multiple layers of geosynthetic reinforcements.

- Number of the reinforcing layers is an important parameter to be studied. Increasing the number of the reinforcing layers increases the bearing capacity of the reinforced soil. In this study, using four layers of the reinforcing material is considered the optimum number of the reinforcing layers.

- Distance between the reinforcing layers is an important parameter to be studied. Reducing the distance between the reinforcing layers, increase the bearing capacity of the reinforced soil. In this study, within the effective reinforced zone, the optimum spacing between the reinforcing layers is considered half the width of the footing.

\section{References}

[1] J., Binquet and K.L., Lee, "Bearing capacity tests on reinforced earth slabs" Journal of Geotechnical Engineering Division, ASCE 101, vol. 12, pp. 1241-1255, 1975.

[2] R.J., Fragaszy and E., Lawton, "Bearing capacity of reinforced sand subgrades" Journal of Geotechnical Engineering Division, ASCE 110, vol. 10, pp. 1500-1507, 1984.

[3] C.C., Huang and F., Tatsuoka, "Bearing capacity of reinforced horizontal sandy ground" Geotextiles and Geomembranes 9, vol. 1, pp. 51-82, 1990.

[4] K.H., Khing, B.M., Das, V.K., Puri, E.E., Cook and S.C., Yen, "The bearing capacity of a strip foundation on geogrid reinforced sand", Geotextiles and Geomembranes 12, pp. 351-361, 1993. 
[5] T.,Yetimoglu, J.T.H., Wu and A., Saglamer, "Bearing capacity of rectangular footings on geogrid-reinforced sand" Journal of Geotechnical Engineering, ASCE 120, pp. 2083-2099, 1994.

[6] J.O., Akinmusuru and J.A., Akinbolade, "Stability of Loaded Footings on Reinforced Soil" Journal Of Geotechnical Engineering Division ASCE 107, vol. 6, pp.819-827, 1981.

[7] M.T., Omar, B.M., Das, V.K., Puri and S.C., Yen, "Ultimate Bearing Capacity of Shallow Foundations on Sand with Geogrid Reinforcement" Canadian Geotechnical Journal 30, pp.545-549, 1993.

[8] M.T., Adams and J.G., Collin, "Large Model Spread Footing Load Tests on Geosythetic reinforced Soil Foundations" Journal of Geotechnical and Geoenvironmental Engineering, ASCE 123, pp.66-72, 1997.

[9] A., Kumar and S., Saran, "Closely Spaced Footing on Geogrid Reinforced Sand" Journal of Geotechnical and Geoenvironmental Engineering 129, vol.7, pp.660-664, 2003.

[10]A.K., Bera and A., Ghosh, "Regression Model for Bearing Capacity of a Square Footing on Reinforced Pond Ash" Geotextiles and Geomembranes 23, vol.3, pp.261285, 2005.

[11] Madhavi Latha and Amit Somwanshi, "Bearing Capacity of Square Footings on Geosynthetic Reinforced Sand" Geotextiles and Geomembranes 27, pp.281-294, 2009.

[12] G.P. Raymond, F.E. Comos, "Repeated load testing of a model plane strain footing", Canadian Geotechnical Journal 15 (1978)190-201.

[13]H. Poulos, F. Aust, E. Chua, "Bearing capacity on calcareous sand", Research Report, University of Sydney, 1986.

[14]V.A. Guido, D.K. Chang, M.A. Sweeney, "Comparison of geogrid and geotextile reinforced earth slabs", Canadian Geotechnical Journal 23 (1986) 435-440.

[15]M. El Sawwaf, "Experimental and numerical study of eccentrically loaded strip footings resting on reinforced sand", Journal of Geotechnical and Geoenvironmental Engineering 135 (10) (2009) 1509-1518.

[16]B. Yeo, S.C. Yen, V.K. Puri, B.M. Das, M.A. Wright, "A laboratory investigation into the settlement of a foundation on geogrid-reinforced sand due to cyclic load", Geotechnical and Geological Engineering 11 (1993) 1-14.

[17]B.M. Das, V.K. Puri, M.T. Omar, E. Evgin, "Bearing capacity of strip foundation on geogrid reinforced sand-scale effects in model tests", in: Proceedings of the Sixth International Conference on Offshore and Polar Engineering, vol. I, Los Angeles, USA, 1996, pp. 527-530.

[18] A.F.Zidan, "Numerical study of Behaviour of circular footing on geogrid-reinforced sand under static and repeated loading", 2011. 